\title{
Strategy as Dialogue and Engagement
}

\author{
Timo Aarrevaara, Rómulo Pinheiro, and Johan Söderlind
}

\section{INTRODUCTION}

Interest in organisational strategy spans more than half a century and is a central topic in the business management and organisational literature (Miles et al. 1978; Chandler 2003). Within the organisational field of higher education, particularly in Northern Europe, strategic planning has only emerged in the last two decades or so, as a result of governmental reforms inspired by 'new public management' (Mouwen 2000; Rip 2004; Salminen 2003), leading to the rise of strategic science regimes. Strategy could be broadly defined as pertaining to 'a deliberate conscious set of guidelines that determines decisions into the future' (Mintzberg 1978,

\section{T. Aarrevaara $(\bowtie)$}

Faculty of Social Sciences, University of Lapland, Rovaniemi, Finland e-mail: timo.aarrevaara@ulapland.fi

R. Pinheiro

Department of Political Science \& Management, University of Agder, Kristiansand, Norway

e-mail: romulo.m.pinheiro@uia.no

J. Söderlind

School of Industrial Engineering and Management, KTH Royal Institute of Technology, Stockholm, Sweden

e-mail: johanso2@kth.se

(C) The Author(s) 2019

R. Pinheiro et al. (eds.), Reforms, Organizational Change and

Performance in Higher Education, https://doi.org/10.1007/978-3-030-11738-2_7 
935). Mintzberg makes an important conceptual distinction between 'intended' (the aim and goals) and 'realised' (the means used and the results) strategy and refers to the strategy formulation process as 'a pattern in a stream of decisions' (Mintzberg 1978, 935).

In other words, strategies are instruments of change, and within higher education institutions, the responsibility of academic leaders who carry them out is to maintain the operation, but at the same time, to embrace change opportunities. Strategies are also flexible tools for dealing with a range of requirements and threats and are related to how universities focus on funds allocation, financial stability, management structure, central operation units, and operational monitoring (Uslu 2018). It is important to ensure the wide support of key stakeholders because the implementation of strategies requires dialogue and compromise (Whittington 2006). Academic staff, in particular, might find that the strategies adopted clash with their own strategic interests and motivations and that they are of low relevance to their performance (Elena-Pérez et al. 2011). The highly dynamic and competitive environment in which universities and other higher education institutions operate places emphasis on the need to adopt strategic focus areas, increase the diversity of the funding base, identify and engage with a multiplicity of internal and external stakeholders, and prepare operational alternatives for performance management (Aarrevaara 2015). Given the traditionally high levels of structural (and cultural) decoupling within universities (Birnbaum 1988), academic subunits and individuals tend to resist attempts to set strategic management priorities at the level of the central administration (Pinheiro and Stensaker 2013). Recent developments suggest that, as a result of managerialism, centralisation is on the rise within universities/subunits (Deem et al. 2007), and that the strategic management of people, resources, and values is one such manifestation (Fumasoli et al. 2015).

This chapter sheds light on two key aspects:

1. Who gets involved in strategic processes in Nordic universities?

2. To what extent do strategies affect academic and managerial behaviour?

To answer these questions, we have developed a conceptual framework that includes several theoretical perspectives on how to interpret strategy work within universities. The data for this chapter were drawn from 
interviews ${ }^{1}$ and a survey with academics, managers, and administrators based at public universities in Finland, Norway, and Sweden. This was part of a much larger project focusing on the performance effects related to changes in leadership and managerial structures of Nordic universities in recent times (consult the introduction to this volume). Their views constitute their perceptions about the key starting points and identification of the strategy, the importance of basic tasks, changes in strategic management, engagement in the processes around a strategy, and the importance of strategies for performance.

Most Nordic universities have a strategic platform, one composed of aims, ambitions, and key priorities in the realms of teaching, research, and the third mission (Pinheiro and Stensaker 2014; Pinheiro et al. 2016). Yet, the importance of strategies only became a key factor in universities' activities around the late 1990s. Since then, the importance of university structures has risen alongside the academic aspects of university performance (Amaral et al. 2003). Strategies and structures are related in the sense that aims and priorities result in new forms of resource allocation and the redefinition of internal tasks, roles, and responsibilities. In the Nordic countries, this trend has been reflected in the strengthening of institutional autonomy in legislation, while at the same time, the emphasis of strategies has been on performance management (Gornitzka et al. 2004). Because of these elements, strategies have a central role in defining the performance that is desired in Nordic universities.

\section{Perspectives on Strategy}

This chapter focuses on what a strategy is and how is it defined, paying particular attention to the multi-level approach of organisational design (Frost et al. 2016). Thus, we first look at strategy from the point of view of the structure, whereby the meaning of the strategy is a constructive organisational form. The starting point is then the shared commitment to the implementation of the strategy and an element of organisational development. From the perspective of the university structure, strategy is an arena that aggregates diverse interests into common goals.

From a structural perspective, university strategy formulation appears to be a rational process, meaning a series of predetermined decisions about

\footnotetext{
${ }^{1}$ Interviews were held at six case institutions, two per country: one classic 'flagship' university and another with a more 'regional' character.
} 
how to reach specific ends by resorting to a set of means, what March and Olsen term 'the logic of consequences' (March and Olsen 2006). Universities, however, also carry out a wider social agenda, and in the Nordic countries, their funding and mission are closely linked to wider public interest (Pinheiro et al. 2016). Therefore, universities' strategies are not purely rational practices, but their creation and implementation also involve political choices and limitations (Pfeffer and Salancik 1974). These factors of political choices and limited rational practices do not necessarily optimise performance. Universities have unprofitable activities and/or disciplines that may be unreliable from the point of view of the university's internal performance. For example, costly educational programmes can be an effective public policy instrument for reasoning, such as analysis based on income, gender, or place of residence, and unprofitable performance can be valuable from the perspectives of regional development strategies and socio-economic regeneration programmes (Habibov and Cheung 2017; Lebeau and Bennion 2014).

A second perspective of the strategy is based on processes that either change or maintain the activity. From this point of view, the strategies appear in analytical and logical constructions, whereby the consequences of the strategy are understandable to the intra-organisational practitioners and extra-organisational actors (Whittington 2006). The processes that form the strategy are based on a dialogue that broadly considers stakeholders' views and aspirations. Strategic processes reinforce the elements of negotiation and compromise but, at the same time, reduce institutionallevel solutions (Aarrevaara and Dobson 2013; Pinheiro 2015). If the strategy is largely based on compromise, elements such as transformation may remain weak in the strategy. This is why universities' ability to undertake reform and organisational change, as well as significant new opportunities for focusing, as a part of their strategy is important.

Our third perspective is based on the outputs that the strategy seeks to influence. We interpret the output as an agreement between the internal and external actors of the university, whereby the strategy identifies the organisational goals and the instruments to reach them. From this point of view, university strategies might move universities towards complex and competitive knowledge marketplaces (Pucciarelli and Kaplan 2016). The outputs defined in the university strategies will modify the university's power relations and produce engagement with organisational values. Further, university strategies are arenas within which to interact with external stakeholders and cope with societal contingencies (Aarrevaara et al. 2017; Fumasoli et al. 2015). Strategies can determine which disci- 
plines or cross-disciplinary research themes are at the heart of the strategy so that they can be focused on strategy-based resources. The key to this strategy is that resources (and resource redistribution) generate change and results in focused areas (Covaleski and Dirsmith 1988).

In this chapter, we aim to analyse the data by applying the theoretical and conceptual framework for strategy formulation. This will be done by discussing the literature on strategy as practice and analysing the interviews and survey results as discussed in the first chapter of this volume.

\section{Engagement in the Strategy Process}

Our starting point for analysing strategy formulation is to draw a distinction between strategy engagement and strategy as dialogue. Both questions were asked as part of the semi-structured interviews and the survey. Engagement refers to who the key players in strategy formulation are. Strategy as dialogue, in turn, refers to the process and content of the strategy, as well as the ways in which actors are engaged with, and committed to, strategy formulation. In previous reporting of FINNUT ${ }^{2}$ project data, attention has been paid to the fact that Finnish professors, as the most senior academic staff, have a wider opportunity to influence strategic processes than they have regarding resource allocations (Pekkola et al. 2017). The early engagement of the strategy is, therefore, much more the work of senior research and teaching staff and those in management and administrative positions than those in other academic posts. In addition, Pekkola et al. (2017) have demonstrated that professors in management positions have experience in preparing for strategy, which is similar to the responses of administrative managers. Above all, senior academics also enjoy relatively more professional autonomy regarding the strategy process (Kivistö et al. 2017).

The FINNUT data clearly indicate that participation in strategy formulation is greater at the academic unit level (departments or equivalent) and lowest at the level of the university (see Fig. 7.1). In Sweden, nearly 60\% of the respondents reported that they actively participated, whereas in Norway, only about $40 \%$ did so, with Finland in between. The data reveal that in practice, and unsurprisingly, engagement in strategy formulation is most common amongst administrative staff and academic managers and lowest amongst academics. Except for Norway, the countries reported

\footnotetext{
${ }^{2}$ FINNUT is a long-term programme for research and innovation in the educational sector under the auspices of the Norwegian Research Council. The programme funds research on a wide spectrum from early childhood education and care to higher education and adult learning.
} 
60.0

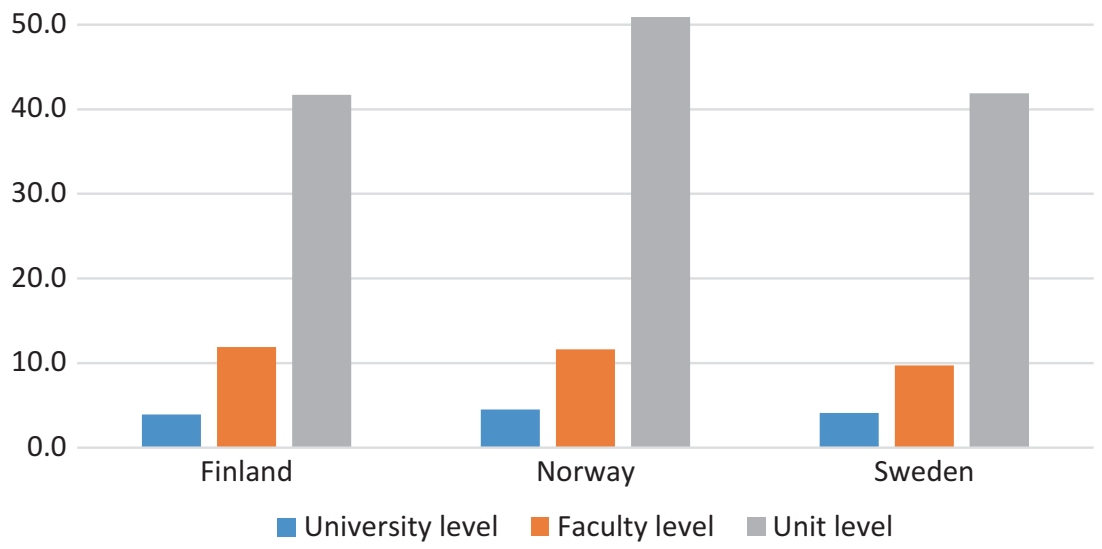

Fig. 7.1 Participation in strategy formulation (percentage of those academics who agreed with values 4 and 5 ; scale ranged from 1 (no participation) to 5 (strong participation)

greater levels of participation with unit-level strategy formulation amongst professors when compared with other academic groups (associate professors, assistant professors, senior lecturers, etc.).

Also, from the Finnish interviews, we can verify that the engagement of professors who have only academic responsibilities is different from their engagement in strategy formation (see Pekkola et al. 2017). Early engagement is typical for professors with managerial responsibilities, such as deans or the equivalent. However, the roles for research and teaching professors with no managerial responsibilities are different. It is evident that the role of university strategies is understood in a range of ways. Some informants see the strategies as beacons for everyday activities at the unit level, while the rest of the interviewees connected the strategies with institutional views on the universities' core functions.

For me, the strategy is that we are doing high-level international research, so it is not so much about the university strategy that we're dealing with. (Academic, flagship, FI)

We write an annual report, so we write to the Ministry and, there, the [strategic] thematic efforts will also be reflected in what we report. The univer- 
sity board is very close and asking for continuous updates, and it is very clear that they want to see that the strategy is reflected in all the work that is happening in the organisation. Then, at the next university board meeting, there is a separate discussion about the implementation of strategies. (Manager, regional, NO)

I like the idea of living a strategy. So, when you make all these everyday decisions, you have to ask yourself, does this contribute to an increase in the number of publications, increased internationalisation, and increased external funding? (Regional, Manager, SE)

The preparatory committees for strategy processes are appointed by those who are attached to administrative and academic leadership professions. Membership in these committees is not merely formal but is related to local practices (Johnson et al. 2007). Even if the strategy of early engagement is launched on the basis of the importance of academic units, commitment amongst other staff may be weak. Such a situation arises particularly when academic staff should be the ones empowered to implement a strategy that has already been decided on (Kotter 1996). This creates the need for a specific strategy to be deployed at later stages. However, those who do not have administrative duties in academic positions are not necessarily obligated to commit themselves to the management and management policies.

Participation in strategy formulation at the university level and across all three countries is very low (5\% for all categories), and at the faculty level, the involvement in strategy also remains low (overall, 12\%). This indicates that in the academic units engagement is low, especially regarding university-level strategies. As expected, academic staff engage more in strategy making at the unit level, ranging between $25 \%$ and $50 \%$. Professors score the lowest, with only $25 \%$ being involved in strategy formulation. Associate professors are the most involved at the university, faculty, and unit levels. What is more, associate professors also indicate that they have the greatest influence on strategy formulation at all levels when compared to their more senior and junior counterparts. That said, overall influence over strategic matters remains quite low at all levels, except for almost half of associate professors at the unit level and about one-third of 'other' at the unit level. Professors also scored the lowest at the unit level, with only about one-quarter of respondents reporting that they can influence strategy formulation. 
Turning now to the qualitative data, some of those interviewed indicated that strategies are primarily formulated to please external stakeholders and enhance the accountability of universities to the government, as the main funding source. In some interviews, the universities were also found to be successful organisations before the introduction of institutional strategies. The following responses from the interviews are concerned with internationalisation and core functions such as teaching and research.

The performance reflects government policy, and our main funding source is the Ministry of Education and Culture. I have to report [to our staff] on the policy of the Ministry. That is how we try to anticipate the changing of the operational environment. In this way, we are able to adapt strategies and operational programmes for funding. (Academic, regional, FI)

Sometimes we have experienced that it is a little difficult to find a connection between strategy and what we see as our opportunities. For example, we are now very ambitious on internationalisation, but we are not aware of priorities and resource usage and so on. (Manager, flagship, NO)

However, other informants were doubtful of the relevance of university strategies for the practical work of teachers and researchers. From this perspective, academics as internal stakeholders are not necessarily motivated by the content of university strategies per se, although their motivations may coincide with the strategies.

The staff and student bodies and also our other stakeholder groups [participated in the strategy formulation process], and it was applicable to them. On the other hand, a certain amount of work was done [in strategy preparation] by a rather large group [of administrators]. But in any case, they studied the earlier work of actors, and as a result, the draft was a little more focused. Finally, we have reached the stage that we are now at. This is an inclusive project, and of course, in practice, the decisions of the academic unit leadership, dean, and rectors of the university will close the case. (Academic, regional, FI)

So, if the deans and the Rector say that we should have a commitment and that we agree with it, so there are expectations that we put off and that we have strategic funds. So, I have ... not very much, but I have some strategic funds that I use in the faculty.... So I can allocate these on the basis of quality, but also, for example, around the [strategic] thematic area ... I have strategic space [room to manoeuvre] for it. (Manager, flagship, NO) 
The question is whether [the goals in the strategy] would have been part of my work anyway, because I consider them important. (Academic, regional, SE)

Returning to the survey data, assistant professors are the staff category with the perceived least input on decision-making processes. Academic staff seem to be most responsive to unit strategies: the evaluation of around $60 \%$ of assistant professors, associate professors, and professors was that they align their academic behaviour to meet the goals in the unit strategies. Over 30\% of the assistant professors, professors, and 'other' also responded that they align their academic behaviour to meet faculty strategies, while associate professors scored slightly lower, at $29 \%$. Also slightly lower was the perceived alignment of academic behaviour with university strategies (average 30\%). It seems that academics with managerial roles are more responsive to the strategies than the academics in general. The majority of the academic managers $(85 \%)$ responded that they align their managerial behaviour to meet the goals of unit strategies, $62 \%$ to meet the goals of faculty strategies, and $47 \%$ to meet the goals of university strategies. On average, $87 \%$ of professors with managerial responsibilities reported that they follow strategies.

Strategies at different levels (university, faculty, and academic unit) were familiar to the managers at distinct hierarchic levels in the universities. In general, members of the academic staff were not as familiar with these, but some recognised that strategies provide frames for academic work, while others thought these were just formalities that are disconnected or decoupled from daily work. An academic from the latter group remarked that he could have used the strategies more strategically to clarify his research and when applying for research funding. Unsurprisingly, managers and administrators were found to be more dependent on the strategies to guide them in their daily work priorities. The dialogue between managers and academics is seldom based on consensus, as illustrated below.

My wish is to think that I can take into account different perspectives. And even though the administration seems to be trying to streamline our activities, in practice, sometimes it means doubling the workload. Then you need a person who can say that you know how this really is the [way the] process [should be] going. (Academic, regional, FI)

Yes, it [the strategy] is important because it provides a frame for what should be prioritised and what we should have as the main focus. (Manager, flagship, NO) 
So I guess it is good both for those who are motivated and those who think that the university is moving in the wrong direction because they are also becoming sharper in this process. (Manager, flagship, SE)

As for the process of decision-making and developing strategies, for the most part, it is described by interviewees as democratic and open. That said, it is still seen as a top-down process. Suggestions for strategies were made at the highest level and developed down the line in the hierarchy. In this regard, the data reveal significant differences between the engagement practices across Nordic universities. For example, at the department level in the Norwegian cases, a broad range of academics were involved, and they reported open discussions amongst staff. In Finland and Sweden, discussion and involvement at the department or equivalent academic unit level was greater than in other areas. Some pointed to the importance of collegial and informal structures. In all three countries, the stakeholders in the local community were also invited to participate in the strategy formulation process.

\section{Dialogue as Practice}

The so-called practice turn in the approach to creating strategy has shifted the focus of debate from an individualist to a more broadly societist perspective, with task dynamics, open information, and influence (Whittington 2006; Pacheco and Newell 2018). This also means a more integrated understanding of the practice of strategy within organisations. The broader meanings of the strategy are embedded in the work of the practitioners so that the perspective can be simultaneously viewed from intra-organisational and extra-organisational perspectives (Whittington 2006). This is of great importance in how practitioners of the strategy produce concepts of strategies. The 'linguistic turn' in this approach to strategy brings the opportunity to unleash the strategy and its instruments without needing to follow cultural and historical practices. In this way, the strategy as practice perspective provides the opportunity to build and implement a strategy without organisational memory and, instead, focuses on what the local actors are actually doing (Jarzabkowski and Spee 2009).

The linguistic turn has questioned the meaning of the strategy as a form of rational planning by emphasising the importance of strategising the dialogue between practitioners. According to this perspective, the dialogue allows practitioners to contribute to the organisations and stakeholders to a greater extent than their original planning would have done (Harisalo and Aarrevaara 2015). Dialogue is especially necessary when actors can engage 
in the strategy formulation at an early stage. However, the FINNUT data clearly show that the dialogue is inadequate. In practice, most commonly, it is the senior academic and administrative executives who influence the dialogue at the faculty and university levels, with academic engagement declining as one moves up the organisational ladder. Moreover, based on the interviews, it is clear that the majority of those in academic posts only very rarely have a stake in the strategy formulation process. Thus, in the case of Nordic universities, the dialogue does not seem to work, at least in the early stages of the strategy formulation process, as a convergence of different personnel groups and strategic interests and as predicted in the literature (Whittington 2006; Lebeau and Bennion 2014).

Figure 7.2 shows that strategy formulation can be implemented through dialogue at the academic unit level. On the other hand, the numbers of actors at the faculty and university levels are substantially reduced. That said, there are significant variations amongst the three countries. Unit-level influence is highest in Sweden and Finland and lower in Norway. At the faculty level, Finnish and Swedish academics reported greater levels of influence when compared with Norway. Finally, at the level of the university as a whole, Finland and Sweden lead the pack, with Norway lowest overall. In Finland and Sweden only, over two-thirds of the respondents believe that they engage in the strategy process at some level.

60

53.4

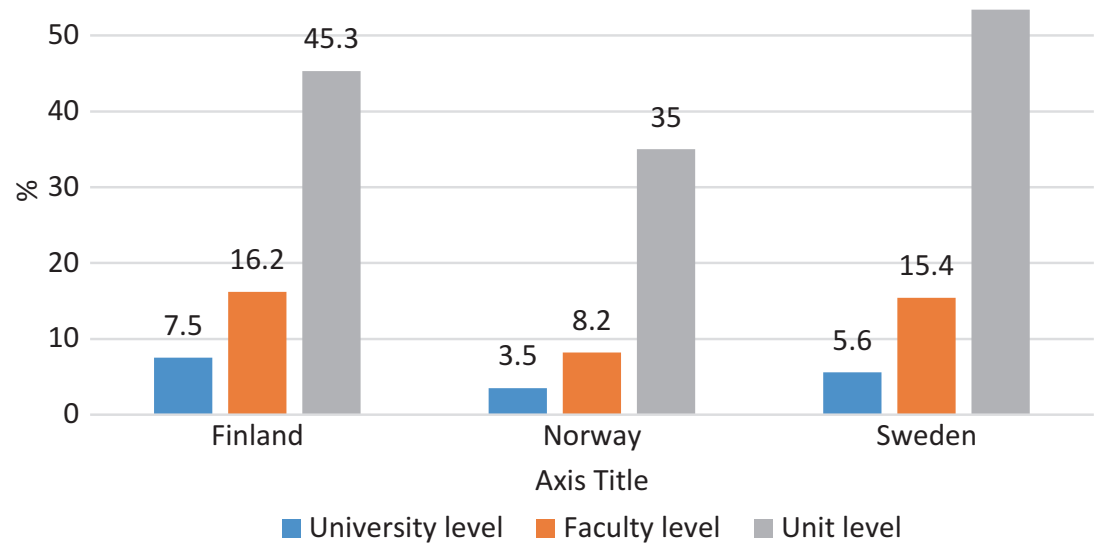

Fig. 7.2 Influence in strategy formulation (percentage of those who agreed with values of influence in strategy formulation, where 4 is some influence and 5 is strong influence) 
More typical for Finnish interviewees was the emphasis on funding mechanisms and financial influence in societal interaction and university governance. Most of the interviewees recognised the role of external stakeholders and their influence on university governance.

Of course, the fact is that there are external non-university members on the university board. No doubt, they are influenced by the government in their views. And this is also the case regarding donations, and they often determine whether to use donations or benefit from the interest on donations. (Manager, flagship, FI)

In the case of Norway, strategic work emerges from the interplay between many actors within the university as well as key external stakeholders. Compromise seems to be reflected in the generic nature of the goals being adopted, in line with the traditional democratic model of universities. In open dialogue, informal structures and collegial bodies are thought to play a key role.

It is first and foremost the dean who has both pulled the [strategy] process and has had an influence in that round, I would like to say. But we have had the opportunity to have an input. I was involved in a working group that looked at one of the educational areas. So that way, you can say that I have had some opportunity to influence. What will come out of it, that's another matter. (Manager, flagship, NO)

One Swedish manager suggests that strategies are formulated primarily to please external stakeholders and for enhancing the accountability of universities. This manager downplayed the practical use of strategies for university actors by noting that the university has had considerable success during a period when no strategy existed.

If you want to see what came out of it [the strategy work] here at the local level, it simply became documents. (Academic, regional, SE)

\section{Strategy as Practice}

Strategy as practice examines the evolution of strategies by studying their formulation, planning, and implementation. Attention is not so much on the consequences of the strategy, such as the economic and organisational 
effects. Instead, strategy as a practice draws attention to practical work as praxis episodes in formal meetings or informal episodes. From this perspective, practical work is either relevant or does not fit the focus of the strategy. Similarly, individuals can determine their position by combining work practices to understand the various domains of human activity and their interrelation to strategies. In this chapter, and following the interview and survey data from the FINNUT project, strategy as practice focuses on the social dimension and social interactions occurring at different levels of the university. Thus, strategy formation and implementation are not key factors, but staff, management, and stakeholder relations are.

However, it has been noted that strategy work is intermittent. The benefits of strategy work provide only temporary revitalisations of the discussions of organisational objectives, which are quickly forgotten once the strategy has been decided upon. The meaning of strategy was unclear for many of the Finnish interviewees, but some emphasised benefits of a strategy. Surprisingly, this was not necessarily dependent on the interviewees' position or rank. Some interviewees were critical of the whole strategy process. The problem, as raised in the Finnish interviews, is the poor connection between strategies and core functions. Thus, for the Finnish interviewees, the top-down process of strategy management or the discussion at different levels has not been a key problem. The main concern is how the strategy links to university performance, as revealed by the following comments.

We implement the strategy, because excellent research is part of the University strategy. And really, social impact is certainly a matter, and it is part of my own strategy. When we publish the research outcomes, or discuss with scholarly community or patient organisations, we are implementing University strategy. (Academic, flagship, FI)

The problem with strategic plans is that, at first, we worked hard on it for a year, then it was decided upon, and then it was kind of added to the files. (Manager, flagship, SE)

The accounts from Norway reveal that social relations are aligned with the notion of the university as a more unified, strategic actor rather than a collection of individual units and diverging strategic interests.

So we work on many levels. And then we try to get it together [coherent whole], so the strategic education committee coordinates this, and then we 
get it a little bit, and then we get the faculties to help each other out [based on] what they are good at, so they borrow from each other a little. So we try to build a form to work inside and content such that we are as strategic and coordinated as possible and that we make the most of both time and money. (Manager, regional, NO)

\section{Changing Purpose of the Strategy}

From a rational-instrumental theoretical perspective (Christensen et al. 2007), strategy documents are considered to be instruments to reach organisational goals, and actors are expected to align their behaviour to match them. Table 7.1 shows the extent to which academic staff and managers state that they align their behaviour with the goals presented in the strategies. It shows that, to a large extent, managers align their behaviour with unit- and faculty-level strategies, but only to some extent with university-level strategies. This confirms the message from the interviews that, for actors in departments or equivalent academic units, the universitylevel strategies are mostly symbolic rather than core components of their daily working strategy. The survey data reveal that academic departments' strategies are more strongly based on engagement and dialogue than are university-level strategies.

Table 7.1 also shows that academics, in general, align their behaviour to strategy goals to a lesser degree than do managers. Still, more than $80 \%$ of academics in the three countries stated that their behaviour was aligned to goals in unit strategies, compared to about one-third in the case of university strategies. When it comes to academics, country differences are less than those seen in relation to managers. However, academics in Finland, Norway, and Sweden have loyalty towards hierarchically lower-level strategies. In Table 7.2, it can be seen that managers reported their behaviours clearly meeting their goals more often than academics at all university levels.

Respondents across the sample indicated that strategies have become increasingly prominent since the early 2000 s, particularly in the last decade. Competition and the need to coordinate and orchestrate activities across the board, as well as assess performance, come to the fore as key purposes for strategic exercises, which, on the whole, have also become more top-down and central to university life.

For me personally, performance in teaching means that, above all, the process to bring the message - so to say that students will learn - is the most 
Table 7.1 Academics' views to meeting goals of strategies (percentage of those who agreed with values 4 and 5 )

\begin{tabular}{lccc}
\hline & Finland & Norway & Sweden \\
\hline $\begin{array}{l}\text { I align my academic behaviour to meet goals in university } \\
\text { strategies. }\end{array}$ & 31.8 & 29.9 & 28.2 \\
$\begin{array}{l}\text { I align my academic behaviour to meet goals in faculty } \\
\text { strategies. }\end{array}$ & 41.0 & 34.9 & 36.8 \\
$\begin{array}{l}\text { I align my academic behaviour to meet goals in unit } \\
\text { strategies. }\end{array}$ & 64.2 & 60.5 & 66.5 \\
\hline
\end{tabular}

Table 7.2 Administrators' views to meet goals of strategies (percentage of those who agreed with values 4 and 5 )

\begin{tabular}{lccc}
\hline & Finland & Norway & Sweden \\
\hline $\begin{array}{l}\text { I align my management behaviour to meet goals in university } \\
\text { strategies. }\end{array}$ & 49.5 & 46.7 & 46.5 \\
$\begin{array}{l}\text { I align my management behaviour to meet goals in faculty } \\
\text { strategies. }\end{array}$ & 69.7 & 61.6 & 60.6 \\
$\begin{array}{l}\text { I align my management behaviour to meet goals in unit } \\
\text { strategies. }\end{array}$ & 86.9 & 84.1 & 85.6 \\
\hline
\end{tabular}

important result. In research, the most important issue is publishing. (Academic, regional, FI)

There is not much strategy on teaching ... it's a good idea to give good candidates and teaching and such things. And of course, it should be relevant that the students should experience what is relevant ... So, yes, you cannot just decide to get so and so many research projects; it's absolutely impossible then. (Academic, flagship, NO)

This proves that the researchers and the departments know what to do as a teacher and researcher. We know what to do, and we struggle, and we are successful during a period, and then perhaps we may stagnate for a period. (Manager, flagship, SE)

\section{InSTITUTIONAL STRATEGIES AND ACTORS}

This section deals with a theme that focuses on strategy at the university level and on the university as a strategic actor. University strategies are essential tools for determining how institution-level goals are enforced in 
academic units. The alternative is traditional federalist university governance, through which the definition of essential and meaningful work is defined at the level of academic units (Balbachevsky and Schwartzman 2011). The key strategy implementation of this determination is resource allocation. The data presented in this section provide an explanation of how strategy setting and allocation of resources can result in a strong institution at the faculty and academic unit levels. This phenomenon is apparent in the respondents' perceptions of how strategic goals affect the allocation of resources at the university, faculty, and academic unit levels (Fig. 7.3).

The data show slight variations in the ways in which strategic goals affect the allocation of resources. In Finland and Norway, strategies are more geared towards university-level initiatives, such as strategic research areas and the establishment of central level units, such as for research, internationalisation, and other activities. In contrast, the data for Sweden suggest that strategic resource allocations are more prominent at the faculty level. Accounts from the interviews show that managers play a critically important role in implementing strategies and assessing strategic results and that there is an increasing tendency for the coupling of core activities and resources with high-level/strategic goals at the university and faculty levels.

The data suggest that in one way or another (i.e. directly or indirectly) university-level strategies have a tendency to dominate over academic unit

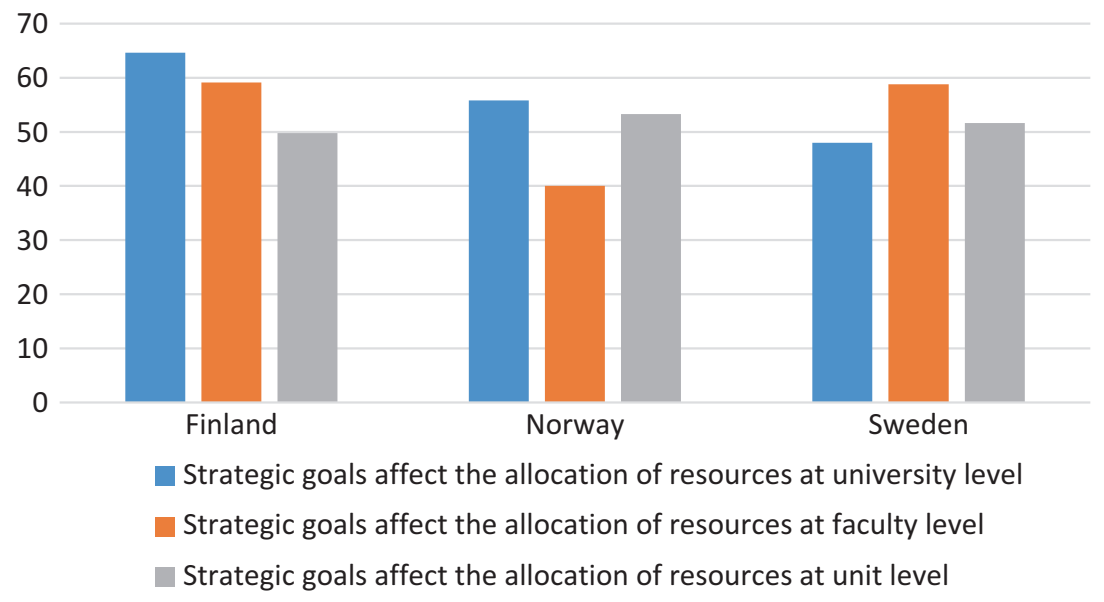

Fig. 7.3 Respondents' views on how strategies affect resource allocation (percentage of those who agreed with values 4 and 5 ) 
strategies, suggesting that the relationship between strategies and organisational life has become more top down (hierarchical) than was the case before. In some interviews, there was discussion about how well universitylevel strategies take into account academic units' strategic priorities (specialisation areas) and assets (teaching and research excellence).

We have a new strategy developed by the faculty that will largely follow the university's strategy, support it and, will participate in certain sections where our expertise is best targeted. In these [focus] areas, it is the implementation of the [university] strategy, as well as research and education strategies. And, of course, it also controls the research, that is, especially the strategic funding. (Academic, regional, FI)

Strategies are thought by some, mostly administrators, to be critical tools in processes of change and transformation ('modernisation'), as in the case of mergers. There is also evidence of strategic behaviour by faculties in gaining access to strategic resources, but with them acting as though it is business as usual (decoupling).

Now, I've been in this position for just 2.5 years, as long as we've had this [change process], but I've never ... in any other roles worked so closely on a strategy, and I think it's really necessary when we're now merging. It is so necessary to know where we want to go and that we will all go after the same thing, so I think that in merger processes in particular, [a clear strategy of clear leadership] becomes more important than ever. (Manager, regional, $\mathrm{NO}$ )

It should also be emphasised that discussions are thought to be beneficial for people who disagree with the final strategy formulations, as it provides opportunities to develop alternative arguments about the overall direction of the organisation.

It may not be the strategy documents themselves, but rather the process of getting there and the discussions you have. (Manager, flagship, SE)

\section{Conclusions}

The remit of this chapter was to illuminate two critical aspects underpinning university life in the Nordic countries: who gets involved with strategic processes, and to what extent these processes affect behaviour across 
the organisation. The results based on the FINNUT survey and our interview data indicate that university-level strategies at Nordic universities lack legitimacy. This is because strategy formulation at these universities is based on the complex relationship between the academic departments and the university. These relationships are governed by the setting of objectives, focusing on research and education, as well as on the role of the strategy in allocating the resources required for implementation. Participation in strategy work was found to be unstable, which in turn further weakens the legitimacy of the strategy. The comparative data show that some academic staff are not involved in the strategy process at all, and hence do not relate their daily tasks to the goals and/or values expressed in the strategy.

It seems that in the Nordic countries examined, universities have quite traditional and rational assumptions regarding strategies and strategic work. Academics do not often share this view, as their adherence to the preparation and implementation of the institutional strategies is often accidental. Based on the cross-country data, it can be argued that a strategy has meaning for practitioners and actors in strategy formulation when it is useful to those practitioners. This is particularly apparent in strategy formulation, in which participation is significantly reduced the closer the strategy moves towards the university level. In the three Nordic countries, less than $10 \%$ of respondents reported participating in strategy formulation at the university level, and about half of the academic staff reported participating in strategy formulation at the unit level. For administrators, strategy process and strategy implementation are a more natural part of their work. These findings are aligned with the evidence (both within and outside the Nordic region) that recent reform processes aimed at transforming universities into more coherent, strategic actors (Pinheiro and Stensaker 2013; Ramirez 2006) have resulted in a growing gap regarding the values, practices, and priorities of university managers as compared to those of the academic heartland (Berg and Pinheiro 2016; Pekkola et al. 2017).

The factors highlighted above make it possible to rebuild universities' power relationships, engagement, and organisational values in the preparation and implementation of a strategy (cf. Fumasoli et al. 2015). These factors, in turn, define the directions of a university's future and also legitimise the university's position as an organisation (Deephouse et al. 2008). When academic staff define a strategy for the benefit of individuals or units, there is no common understanding of what the strategy is in any of 
the three Nordic countries. For example, in the Finnish responses, it is typical to criticise the priorities or the profile-based development of the strategy. Some of the respondents remain distanced from the strategy and do not follow the goals or meanings of the strategy in their work.

It is difficult to define the extent to which the strategies enacted in recent years have affected performance in the realms of teaching and research. That said, the so-called strategic turn seems to be associated (goes hand in hand) with a new culture of performativity and accountability (Hansen et al. 2019). However, it is reasonable to conclude that behaviour changes as internal actors (at different levels) align their activities and strategic aspirations with key thematic (strategic) areas to secure additional resources, both people and funding. In this respect, recent reform processes attest to the importance of resource dependencies (Pfeffer and Salancik 2003) in enacting change and transformation within the Nordic university sectors. That being said, there is also evidence of decoupling (Oliver 1991) once academic communities tap into strategic resources; hence, it is difficult to assess the extent to which strategic priorities are in fact guiding academic behaviour.

As regards strategic processes within universities, the FINNUT data sets show that assistant professors and lecturers are the least influential actors in decision-making processes for institutional strategies. Instead, they play a significant role in unit-level strategy work and especially in the grass-roots implementation, or 'localization' (Wedlin and Sahlin 2008), of institutional strategies. Therefore, and on the basis of survey results and interviews, the main observation made is that no single group is fully dominant in strategy formulation despite the increasing role played by certain local agents such as university managers. Similarly, there seems to be no common arena in strategy work where the dialogue takes place. Engagement in university strategy is formed in a dialogue where different groups have different roles and participate at different times according to their social standings within the university (Battilana 2006). If and when the dialogue is successful, the different actors' roles may turn out to be good practices that the university can emulate or institutionalise over time. In those cases in which the dialogue is unsatisfactory and/or it results in inaction or resistance, there is evidence for the belief that academics tend to deny the importance attributed to strategy formulation at the university level.

The data also indicate that without a dialogue and engagement role, the content of strategies is not relevant to Nordic universities. The fact is 
that different types of staff are not involved in the strategy process. In providing similar access for engagement and dialogue, strategy as practice can take place in different contexts for personnel groups and thus produce a strategic process for the university in which internal and external stakeholders become actively engaged. There is a need for scholarly research about the methods and practices through which strategy practitioners can support the engagement of university staff in the process. There is a lack of this knowledge, especially at the university level, where dialogue seems to be weakest. Based on the results outlined in this chapter, academic staff do not accept the university as a strategy-defining actor, and through the interviews and surveys, an interesting question arises as to how performance management practices can support engagement in the strategy formulation process.

Acknowledgements The data presented in the current volume and individual chapters emanate from a comparative study funded by the Norwegian Research Council under its FINNUT flagship program, a long-term program for research and innovation in the educational sector program. The project number was 237782, and the project was titled 'Does it matter? Assessing the performance effects of changes in leadership and management structures in Nordic Higher Education'.

\section{REFERENCES}

Aarrevaara, Timo. 2015. The Finnish Academic Profession in Health-Related Sciences and Social Services. In Professionalism, Managerialism and Reform in Higher Education and the Health Services: The European Welfare State and the Rise of the Knowledge Society, ed. Teresa Carvalho and Rui Santiago, 64-78. London: Palgrave Macmillan.

Aarrevaara, Timo, and Ian R. Dobson. 2013. Movers and Shakers: Do Academics Control Their Own Work? In The Work Situation of the Academic Profession in Europe: Findings of a Survey in Twelve Countries, ed. Ulrich Teichler and Ester Ava Höhle, 159-182. Dordrecht, Germany: Springer.

Aarrevaara, Timo, Janne Wikström, and Peter Maassen. 2017. External Stakeholders and Internal Practices in Departments of Teacher Education at European Universities. Higher Education Quarterly 71 (3): 251-262.

Amaral, Alberto, V. Lynn Meek, and Ingvild M. Larsen, eds. 2003. The Higher Education Managerial Revolution? Dordrecht, Germany: Springer.

Balbachevsky, Elizabeth, and Simon Schwartzman. 2011. Brazil: Diverse Experiences in Institutional Governance in the Public and Private Sectors. In Changing Governance and Management in Higher Education: The Perspectives 
of the Academy, ed. William Locke, William K. Cummings, and Donald Fisher, 35-56. Dordrecht, Germany: Springer.

Battilana, Julie. 2006. Agency and Institutions: The Enabling Role of Individuals' Social Position. Organization 13 (5): 653-676.

Berg, Laila Nordstrand, and Rómulo Pinheiro. 2016. Handling Different Institutional Logics in the Public Sector: Comparing Management in Norwegian Universities and Hospitals. In Towards a Comparative Institutionalism: Forms, Dynamics and Logics Across the Organizational Fields of Health Care and Higher Education, ed. Rómulo Pinheiro, Lars Geschwind, Francisco O. Ramirez, and Karsten Vrangbæk, 145-168. Bingley, UK: Emerald Group Publishing.

Birnbaum, Robert. 1988. How Colleges Work: The Cybernetics of Academic Organization and Leadership. San Francisco: Jossey-Bass Inc.

Chandler, Alfred D. 2003. Strategy and Structure: Chapters in the History of the American Industrial Enterprise. Washington, DC: Beard Books.

Christensen, Tom, Per Lxgreid, Paul G. Roness, and Kjell Arne Røvik. 2007. Organization Theory and the Public Sector: Instrument, Culture and Myth. Milton Park, UK: Taylor \& Francis.

Covaleski, Mark A., and Mark W. Dirsmith. 1988. An Institutional Perspective on the Rise, Social Transformation, and Fall of a University Budget Category. Administrative Science Quarterly 33 (4): 562-587.

Deem, Rosemary, Sam Hillyard, and Mike Reed. 2007. Knowledge, Higher Education, and the New Managerialism: The Changing Management of UK Universities. Oxford, UK: Oxford University Press.

Deephouse, David L., Jonathan Bundy, Leigh Plunkett Tost, and Mark C. Suchman. 2008. Organizational Legitimacy: Six Key Questions. In The SAGE Handbook of Organizational Institutionalism, ed. Royston Greenwood, Christine Oliver, Thomas B. Lawrence, and Renate E. Meyer, 49-77. London: SAGE Publications.

Elena-Pérez, Susana, Ozcan Saritas, Katja Pook, and Campbell Warden. 2011. 'Ready for the Future? Universities' Capabilities to Strategically Manage Their Intellectual Capital. Foresight 13 (2): 31-42.

Frost, Jetta, Fabian Hattke, and Markus Reihlen. 2016. Multi-Level Governance in Universities: Strategy, Structure, Control. Basel, Switzerland: Springer.

Fumasoli, Tatiana, Rómulo Pinheiro, and Bjørn Stensaker. 2015. Handling Uncertainty of Strategic Ambitions-The Use of Organizational Identity as a Risk-Reducing Device. International Journal of Public Administration 38 (13-14): 1030-1040. https://doi.org/10.1080/01900692.2014.988868.

Gornitzka, Åse, Bjørn Stensaker, Jens-Christian Smeby, and Harry De Boer. 2004. Contract Arrangements in the Nordic Countries-Solving the Efficiency/ Effectiveness Dilemma? Higher Education in Europe 29 (1): 87-101. https:// doi.org/10.1080/03797720410001673319. 
Habibov, Nazim, and Alex Cheung. 2017. The Role of University Education in Selecting Active Strategies for Coping with the 2007 Global Crisis in 28 Transnational Countries. International Journal of Educational Development 57: 65-72.

Hansen, H.F., L. Geschwind, J. Kivistö, E. Pekkola, R. Pinheiro, and K. Pulkkinen. 2019. Balancing Accountability and Trust: Higher Education Reforms in the Nordic Countries. Higher Education. Online First. https://doi.org/10.1007/ s10734-019-0358-2.

Harisalo, Risto, and Timo Aarrevaara. 2015. Katalyyttinen pube lautakunnissaTutkimus kuuden suurimman kaupungin lautakunnista. Tampere, Finland: Tampere University Press.

Jarzabkowski, Paula, and Paul Spee. 2009. Strategy-as-Practice: A Review and Future Directions for the Field. International Journal of Management Reviews 11 (1): 69-95.

Johnson, Gerry, Ann Langley, Leif Melin, and Richard Whittington. 2007. Strategy as Practice: Research Directions and Resources. Cambridge, UK: Cambridge University Press.

Kivistö, Jussi, Elias Pekkola, and Anu Lyytinen. 2017. The Influence of Performance-Based Management on Teaching and Research Performance of Finnish Senior Academics. Tertiary Education and Management 23 (3): 260-275. https://doi.org/10.1080/13583883.2017.1328529.

Kotter, John P. 1996. Leading Change. Boston: Harvard Business School Press.

Lebeau, Yann, and Alice Bennion. 2014. Forms of Embeddedness and Discourses of Engagement: A Case Study of Universities in Their Local Environment. Studies in Higher Education 39 (2): 278-293. https://doi.org/10.1080/030 75079.2012.709491.

March, James G., and Johan P. Olsen. 2006. The Logic of Appropriateness. In The Oxford Handbook of Public Policy, ed. Michael Moran, Martin Rein, and Robert E. Goodin, 689-708. Oxford: Oxford University Press.

Miles, Raymond E., Charles C. Snow, Alan D. Meyer, and Henry J. Coleman. 1978. Organizational Strategy, Structure, and Process. Academy of Management Review 3 (3): 546-562. https://www.jstor.org/stable/257544.

Mintzberg, Henry. 1978. Patterns in Strategy Formation. Management Science 24 (9): 934-948.

Mouwen, Kees. 2000. Strategy, Structure and Culture of the Hybrid University: Towards the University of the 21st Century. Tertiary Education and Management 6 (1): 47-56.

Oliver, Christine. 1991. Strategic Responses to Institutional Processes. Academy of Management Review 16 (1): 145-179.

Pacheco, Matheus M., and Karl M. Newell. 2018. Search Strategies in Practice: Influence of Information and Task Constraints. Acta Psychologica 182: 9-20. 
Pekkola, Elias, Taru Siekkinen, Jussi Kivistö, and Anu Lyytinen. 2017. Management and Academic Profession: Comparing the Finnish Professors with and Without Management Positions. Studies in Higher Education. https://doi.org/10.108 0/03075079.2017.1294578.

Pfeffer, Jeffrey, and Gerald R. Salancik. 1974. Organizational Decision Making as a Political Process: The Case of a University Budget. Administrative Science Quarterly 19 (2): 135-151.

- 2003. The External Control of Organizations: A Resource Dependence Perspective. Stanford, CA: Stanford Business Books.

Pinheiro, Rómulo. 2015. The Role of Internal and External Stakeholders. In Higher Education in the BRICS Countries: Investigating the Pact Between Higher Education and Society, ed. Simon Schwartzman, Rómulo Pinheiro, and Pundy Pillay, 43-58. Dordrecht, Germany: Springer.

Pinheiro, Rómulo, and Bjørn Stensaker. 2013. Designing the Entrepreneurial University: The Interpretation of a Global Idea. Public Organization Review 14 (4): $1-20$.

- 2014. Strategic Actor-Hood and Internal Transformation: The Rise of the 'Quadruple-Helix University'? In Global Challenges, Local Responses in Higher Education: The Contemporary Issues in National and Comparative Perspective, ed. Jelena Branković, Manja Klemenčić, Predrag Lažetić, and Pavel Zgaga, 171-189. Rotterdam, the Netherlands: Sense Publishers.

Pinheiro, Rómulo, Lars Geschwind, and Timo Aarrevaara. 2016. A World Full of Mergers: The Nordic Countries in a Global Context. In Mergers in Higher Education: The Experience from Northern Europe, ed. Rómulo Pinheiro, Lars Geschwind, and Timo Aarrevaara, 3-28. Dordrecht, Germany: Springer.

Pucciarelli, Francesca, and Andreas Kaplan. 2016. Competition and Strategy in Higher Education: Managing Complexity and Uncertainty. Business Horizons 59: 311-320.

Ramirez, Francisco O. 2006. The Rationalization of Universities. In Transnational Governance: Institutional Dynamics of Regulation, ed. Marie-Laure Djelic and Kerstin Sahlin-Andersson, 225-244. Cambridge: Cambridge University Press.

Rip, Arie. 2004. Strategic Research, Post-Modern Universities and Research Training. Higher Education Policy 17 (2): 153-166.

Salminen, Ari. 2003. New Public Management and Finnish Public Sector Organisations: The Case of Universities. In The Higher Education Managerial Revolution? ed. Alberto Amaral, V. Lynn Meek, and Ingvild M. Larsen, 55-75. Dordrecht, Germany: Springer.

Uslu, Baris. 2018. Strategic Actions and Strategy Changes in European Universities: Clues from Institutional Evaluation Reports of the European University Association. European Journal of Higher Education 8 (2): 215-229. https:// doi.org/10.1080/21568235.2018.1432370. 
Wedlin, Linda, and Kerstin Sahlin. 2008. The Imitation and Translation of Management Ideas. In The SAGE Handbook of Organizational Institutionalism, ed. Royston Greenwood, Christine Oliver, Thomas B. Lawrence, and Renate E. Meyer, 218-242. London: SAGE Publications.

Whittington, Richard. 2006. Completing the Practice Turn in Strategy Research. Organization Studies 27 (5): 613-634.

Open Access This chapter is licensed under the terms of the Creative Commons Attribution 4.0 International License (http://creativecommons.org/licenses/ by $/ 4.0 /)$, which permits use, sharing, adaptation, distribution and reproduction in any medium or format, as long as you give appropriate credit to the original author(s) and the source, provide a link to the Creative Commons licence and indicate if changes were made.

The images or other third party material in this chapter are included in the chapter's Creative Commons licence, unless indicated otherwise in a credit line to the material. If material is not included in the chapter's Creative Commons licence and your intended use is not permitted by statutory regulation or exceeds the permitted use, you will need to obtain permission directly from the copyright holder.

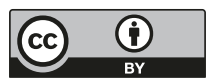

